\title{
Functional properties and Bioactivities of Cleistocalyx nervosum var. paniala berry plant: a review
}

\author{
Mani Iyer PRASANTH ${ }^{1,2}$, Bhagavathi Sundaram SIVAMARUTHI ${ }^{3}$, Monruedee SUKPRASANSAP ${ }^{4}$, \\ Siriporn CHUCHAWANKUL ${ }^{2,5}$, Tewin TENCOMNAO ${ }^{1,2}$, Chaiyavat CHAIYASUT $^{3 *}$ (D)
}

\begin{abstract}
In treating various diseases, natural therapies are widely preferred in the modern era to synthetic drugs as they offer little or no side effects, in contrast to synthetic drugs. However, there is limited scientific knowledge about plants that have a broad range of medicinal properties. Cleistocalyx nervosum var. paniala, native to Thailand and generally known as Ma-kiang in Thai, is one of the least documented plant species. Due to its richness in phenolic compounds, especially anthocyanins, C. nervosum var. paniala has been used in traditional medicine to treat several health complications. The fruits, seeds, and leaves of C. nervosum var. paniala have been reported to exhibit antioxidant, antimicrobial, anti-mutagenic, anti-carcinogenic, anti-aging, and neuroprotective properties. The extracts of $C$. nervosum var. paniala are non-toxic to living systems, and they also can activate the immune system. Moreover, they are widely used in industrial applications, such as in functional food products and in many health products, due to the colored anthocyanin pigments and the anthocyanin benefits of $C$. nervosum var. paniala. However, there is a need to conduct research in this berry species to identify the mechanism behind its medicinal properties. The present review summarizes the functional properties and bioactivities of $C$. nervosum var. paniala based on available scientific information.
\end{abstract}

Keywords: Cleistocalyx nervosum var. paniala; Ma-kiang; antioxidant; neuroprotection; phenolics; anthocyanins.

Practical Application: The manuscript summarizes the beneficial effects of Cleistocalyx nervosum var. paniala, which helps to develop value-added pharmacological products.

\section{Introduction}

Medicinal plants have been used in traditional medicine for the prevention and treatment of several diseases by improving immunity and reducing cellular stress, but scientific documentation in this regard is very limited (Azuma, 1987; Sriwanthana et al., 2007). Cleistocalyx nervosum var. paniala is one of the least documented medicinal plant, which is widely grown in the northern parts of Thailand (Thongma, 2002) and is known to possess immense health benefits, such as antioxidant, anti-mutagenic, anti-carcinogenic, and anti-aging properties (Charoensin et al., 2012; Inboot et al., 2012; Taya et al., 2009; Manosroi et al., 2015; Sukprasansap et al., 2017). C. nervosum var. paniala belongs to the family Myrtaceae. It is endemic or indigenous to Northern Thailand. Its fruits are known for their antioxidant and anti-carcinogenic properties, due to the presence of polyphenols and flavonoids (Leelapornpisit et al., 2004). The characteristic feature of sweet and sour taste and the natural red color makes it a key ingredient in health drinks and functional foods (Patthamakanokporn et al., 2008). About $200 \mathrm{~mL}$ of $25 \%$ C. nervosum var. paniala fruit beverage possess approximately $820 \mu \mathrm{mol}$ of total antioxidants and $74 \mathrm{mg}$ of total phenolic compounds (Patthamakanokporn et al., 2008).
In addition, C. nervosum var. paniala fruit have the ability to scavenge reactive oxygen radicals and ferric ion, thereby reducing antioxidant power as well as up-regulating the expression of endogenous antioxidant enzymes (Sukprasansap et al., 2017).

Cyanidin-3-glucoside is present in many fruits, including red cabbage microgreen, blueberry, blackcurrant, mulberry, cherry, black elderberry, black soybean, chokeberry, and jaboticaba peel, and it has a variety of health benefits as it could mediate inflammatory responses and alleviate obesity and its related complications (Lee et al., 2017). Anthocyanin from blackcurrant was observed to neutralize the cytotoxic effects of nicotine on fibroblast and epithelial cells as well as inhibit the lipopolysaccharide mediated secretion of interleukin- 6 by human macrophages in a dose-dependent manner (Desjardins et al., 2012).

The fruits of $C$. nervosum var. paniala are rich in anthocyanins, which imparts the bright color to the fruit and confers several health benefits: lowers the risk of cardiovascular diseases, diabetes, arthritis, cancer and neurodegenerative diseases (Charoensin et al., 2012; Sukprasansap et al., 2017; Slemmer \& Weber, 2014). C. nervosum var. paniala contains the highest

${ }^{1}$ Age-Related Inflammation and Degeneration Research Unit, Department of Clinical Chemistry, Faculty of Allied Health Sciences, Chulalongkorn University, Bangkok, Thailand

${ }^{2}$ Immunomodulation of Natural Products Research Group, Faculty of Allied Health Sciences, Chulalongkorn University, Bangkok, Thailand ${ }^{3}$ Innovation Center for Holistic Health, Nutraceuticals and Cosmeceuticals, Faculty of Pharmacy, Chiang Mai University, Chiang Mai, Thailand

${ }^{4}$ Food Toxicology Unit, Institute of Nutrition, Mahidol University, Salaya, Putthamonthon, Nakhonpathom, Thailand

${ }^{5}$ Department of Transfusion Medicine and Clinical Microbiology, Faculty of Allied Health Sciences, Chulalongkorn University, Bangkok, Thailand

*Corresponding author: chaiyavat@gmail.com 
amount of cyanidin-3-glucoside (24.06 mg/100 g dry weight) (Sukprasansap et al., 2017) compared with a large variety of fruits and vegetables that are known to have multiple health benefits (Chaiyasut et al., 2016). The malic and citric acid contents of $C$. nervosum var. paniala fruits are reported to be $0.12-0.19$ and $1.57-1.82 \%$ respectively (Liawruangrath et al., 2005). The predominant antioxidants found in the fruits of C. nervosum var. paniala are glucopyranoside, caffeoylquinic acid, gallic acid, monogalloyldiglucoside, methoxymethylgallate and ellagic acid (Nuengchamnong \& Ingkaninan, 2009).

In addition to the fruits of C. nervosum var. paniala, its leaf extracts also have high amounts of phenolic compounds with antioxidant activities (Poontawee et al., 2016). C. nervosum var. paniala fruit extracts contain gallic acid $(35.34 \pm 17.31 \mathrm{mg} / 100 \mathrm{~g}$ of dry weight), catechin ( $346.55 \pm 12.02 \mathrm{mg} / 100 \mathrm{~g}$ of dry weight) and rutin (104.68 $\pm 14.64 \mathrm{mg} / 100 \mathrm{~g}$ dry weight) (Poontawee et al., 2016). Apart from the pulp, the seed of C. nervosum var. paniala also has many potential antioxidants, which have received limited consideration. The seed of C. nervosum var. paniala contains tannins, which have cancer prevention property. However, conditions such as climate, vegetation, soil characteristics, and storage conditions have an impact on the level of antioxidants in the plant (Belancic et al., 1997; Reynolds et al., 1995).

The effect of storage of C. nervosum var. paniala fruits on their antioxidant activity was investigated. Fruits were collected from two different provinces in Thailand, Lampang and Chaing Rai, known for richness with respect to the total phenolic content and antioxidant potential (Patthamakanokporn et al., 2008). Additionally, storage of the fruits at $-20^{\circ} \mathrm{C}$ for 3 months did not reduce the moisture content, phenolic content and the oxygen radical absorbance capacity (ORAC)-based antioxidant activity. However, the ferric ion reducing antioxidant power (FRAP)-based antioxidant activity declined during storage. Similarly, fruits stored at $5^{\circ} \mathrm{C}$ for 10 days showed no changes in moisture and phenolic content, but the antioxidant activity was reduced significantly (Patthamakanokporn et al., 2008), which was attributed to the temperature-induced degradation of anthocyanins (Chaiyasut et al., 2016).
The present study summarizes the overall functional properties and bioactivities of $C$. nervosum var. paniala with recent scientific evidence.

\section{Bioactivities of $C$. nervosum var. paniala}

The major bioactivities reported for C. nervosum var. paniala are shown in Figure 1 and explained in detail here.

\subsection{Anti-oxidant and anti-aging properties}

Supplementation with aqueous extract of C. nervosum var. paniala fruit $(500 \mathrm{mg} / \mathrm{kg}$ of body weight, 5 times/week for 4 weeks) has been reported, due to its heme oxygenase-1 activation and ability to reduce oxidative stress in rat liver, at a high dose, without causing any acute and subacute toxicity (Taya et al., 2009). It is likely that ethanol extract of C. nervosum fruit decreased lipid peroxidation and increased glutathione peroxidase activity in rats (Thuschana et al., 2012).

Likewise, the water fruit extract of C. nervosum var. paniala exhibited total antioxidant capacity, including 2,2-diphenyl-1-picrylhydrazyl (DPPH) radical scavenging capacity assay ( $93.49 \pm 0.24 \%$ scavenging activity), ORAC assay $(91.06 \pm 3.35 \mu \mathrm{mol}$ of trolox/g of dry weight) and FRAP assay (42.89 $\pm 0.85 \mu \mathrm{mol}$ of trolox/g of dry weight). Furthermore, the total phenolic content was $535.91 \pm 0.09 \mathrm{mg}$ of gallic acid equivalent (GAE)/100 g of dry weight, and the total anthocyanin content was $50.49 \pm 0.64 \mathrm{mg}$ of cyanidin-3-glucoside/100 $\mathrm{g}$ of dry weight (Sukprasansap et al., 2017).

The ethanol extracts from the seeds of C. nervosum var. paniala have been reported to contain total phenolic compounds $(173.6 \pm 1.9 \mathrm{mg}$ of GAE/g of dry weight) and total flavonoids (44.2 $\pm 0.2 \mathrm{mg}$ of rutin equivalents (RE)/g of dry weight), with free radical scavenging activity $\left(\mathrm{IC}_{50}\right.$ value of $\left.0.09 \mathrm{mg} / \mathrm{mg} \mathrm{DPPH}\right)$ (Maisuthisakul et al., 2007).

Apart from the fruit and seed extracts, the leaf extracts of C. nervosum var. paniala were also observed to exhibit potent anti-aging and antioxidant activities, which were influenced by the extraction method and age of the leaves. Three different solvents, namely water, ethanol, and chloroform, were used to extract total phenolic compounds and antioxidants from the leaves

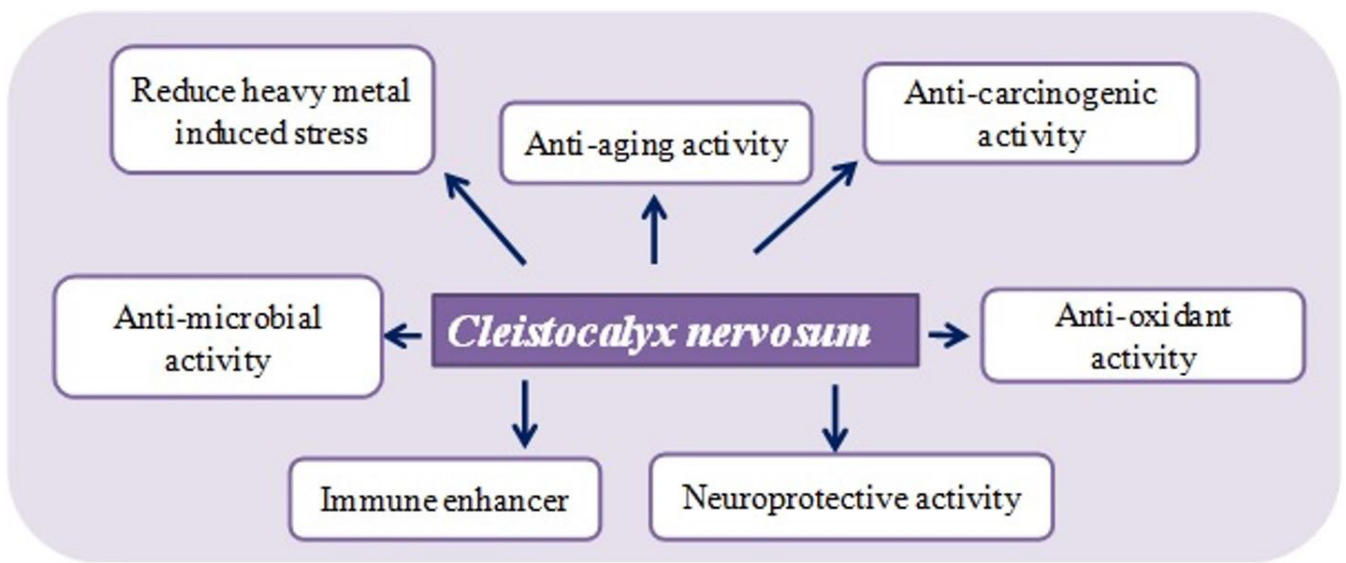

Figure 1. The reported bioactivity of C. nervosum var. paniala. 
of C. nervosum var. paniala in hot and cold extraction methods. The hot methanol and hot water extracts showed maximum yields from old leaves; the yields were 23.96 and $23.93 \%$ respectively. The hot water extract from old leaves had the highest flavonoid content (417.56 $\pm 25.18 \mathrm{mg}$ of QE/g of dried extract), and the hot and cold methanol extracts from old leaves had the highest radical scavenging activity of $0.01 \pm 0.005$ and $0.02 \pm 0.004 \mathrm{mg} / \mathrm{mL}$ respectively. The hot and cold chloroform extracts from old leaves expressed high metal chelating activity $(0.01 \pm 0.001$ and $0.10 \pm 0.01 \mathrm{mg} / \mathrm{mL}$ respectively) compared with other tested extracts. The cold water extract from young leaves showed the highest phenolic content $(1032.49 \pm 18.11 \mathrm{mg}$ of GAE/mg of dried extract). The cold methanol extract from old leaves and the cold chloroform extract from young leaves exhibited tyrosinase inhibiting activity. The cold water extracts from old and young leaves showed gelatinases inhibition activity (Manosroi et al., 2015).

\subsection{Anti-mutagenicity and anti-carcinogenic activities}

The methanol extract from C. nervosum var. paniala seed (MECS) (100-1,000 $\mu \mathrm{g} /$ plate) had no mutagenic effect on Salmonella typhimurium strains of TA98 and TA100. Interestingly, MECS exhibited anti-mutagenic activity on TA98 against aflatoxin B1 (AFB1) and 2-amino-3,4-dimethylimidazo [4,5-f] quinolone (MeIQ) induced mutation and on TA100 strain against 2-(2-furyl)-3-(5-nitro-2-furyl)-acrylamide (AF-2) induced mutation. Moreover, MECS exhibited a chemoprotective effect against diethylnitrosamine-induced hepatocarcinogenesis in rat model (Inboot et al., 2012). Similarly, aqueous extract of C. nervosum var. paniala fruit (AECF) exhibited no mutagenic activity on S. Typhimurium strains of TA98 and TA100 and displayed slight anti-mutagenic activity against $\mathrm{AFB} 1$ and MeIQ induced mutagenesis. The study also showed that AECF was non-toxic to rats up to a concentration of $5,000 \mathrm{mg} / \mathrm{kg}$ of body weight. Unlike MECS treatment, AECF treatment does not exhibit anti-diethylnitrosamine-induced hepatocarcinogenesis in rat (Charoensin et al., 2012).

Diethylnitrosamine and phenobarbital induced glutathione-S-transferase placental form, a marker for the induction and development of neoplastic in rat liver, and preneoplastic lesions were diminished in rats supplemented with $1000 \mathrm{mg} / \mathrm{kg}$ of body weight of an aqueous extract of C. nervosum var. paniala fruits. The level of malondialdehyde in the serum and liver of the experimental subject was also reduced, and the activities of antioxidant enzymes, such as glutathione peroxidase and catalase, in the liver, were improved after the fruit extract of C. nervosum var. paniala treatment (Taya et al., 2014). The chemoprotective effect of the extract may be attributed to its richness in anthocyanins, which are known bioactive compounds having chemopreventive effects against diethylnitrosamine and phenobarbital-induced hepatocarcinogenesis (Bishayee et al., 2011).

\subsection{Anti-heavy metal toxicity}

Cadmium (Cd) causes severe health defects mainly by exhausting the antioxidant system of the host (Poontawee et al., 2016; Valko et al., 2016; Sarkar et al., 2013; Cuypers et al., 2010). Aqueous extract of C. nervosum var. paniala fruit
(AECF) prevented Cd-induced weight loss without altering food intake in rats. AECF supplementation ( 1 and $2 \mathrm{~g} / \mathrm{kg}$ of body weight) significantly reduced Cd-induced renal damages and oxidative stress. Specifically, the levels of nitric oxide and malondialdehyde were reduced in the treated group and the equilibrium of enzymatic and non-enzymatic antioxidants was also maintained. The results suggest that the antioxidant potential of the extract was responsible for the renal-protective activity of AECF (Poontawee et al., 2016). The presence of catechin, rutin, gallic acid, and cyanidin-3-glycoside could be attributed to the anti-oxidative stress property of $C$. nervosum var. paniala fruit (Poontawee et al., 2016; Taya et al., 2014).

\subsection{Neuroprotective property}

Oxidative stress plays a key role in mediating different neurodegenerative diseases, including Alzheimer's disease (Butterfield et al., 2006; Praticò, 2008). C. nervosum var. paniala could play a critical role in mediating the oxidative stress levels of the brain due to the presence of anthocyanins, which are known to cross the blood-brain barrier (Andres-Lacueva et al., 2005). The pre-treatment of cells with C. nervosum var. paniala fruit extracts $(0.05-1 \mu \mathrm{g} / \mathrm{mL})$ for 24 hours significantly protected against glutamate-induced toxicity in HT22 mouse hippocampal neuronal cells. Additionally, glutamate was observed to activate apoptosis-mediated cell death in cells as it increased the protein expression of ER stress-apoptotic markers, including calpain, cleaved caspase-12, and CHOP, which was significantly suppressed by pretreatment of cells with C. nervosum var. paniala fruit extracts. The extract also retained the shape of the neuronal cells, reduced the intracellular ROS levels and maintained the equilibrium of cellular antioxidant enzymes system. Thus, $C$. nervosum var. paniala fruit extracts inhibited glutamate-induced oxidative stress and apoptosis by up-regulating the gene expression of superoxide dismutases, catalase, glutathione peroxidase, and glutathione-S-transferases. These results show that $C$. nervosum var. paniala fruit extracts have neuroprotective properties mediated by antioxidant defense (Sukprasansap et al., 2017).

\subsection{Anti-microbial activities}

An absorbent and desorbent based concentrated ethanol-water extract of C. nervosum var. paniala seed (CEWCE) showed a high content of flavonoids and phenolic compounds compared with the non-concentrated extract. The extract exhibited potent antimicrobial activity against pathogens such as Escherichia coli and S. Typhimurium, which are spiked on fresh-cut cantaloupe. Also, CEWCE protected vegetables from microbial spoilage during cold storage. The results suggest that concentrated C. nervosum var. paniala seed extract could be used in the food processing industry to prevent microbial decomposition of fresh vegetables (Tantratian et al., 2019).

\subsection{Immune enhancement}

Aqueous extracts of C. nervosum var. paniala fruit significantly elevated human lymphocyte proliferation and enhanced the activity of natural killer (NK) cells, which suggest that C. nervosum var. paniala fruit extract has the ability to alter the immune system (Sriwanthana et al., 2007). 


\section{Commercial value and applications}

Fruits of C. nervosum var. paniala are used for the preparation of health drinks. Freeze-dried C. nervosum var. paniala fruit extracts can be used in the food and cosmetic industries. The extracted fruit pulp can be processed as fruit jam with a sweet and sour taste. The essential oil can be extracted from the seeds of $C$. nervosum var. paniala. The residues of the fruits and seeds can be used for the preparation of spa and aromatherapeutic products. Thus, C. nervosum has commercial value without any wastage (Chaisawadi \& Methawiriyasilp, 2008).

Natural hair dyes are preferred by individuals to synthetic dyes due to safety issues. Anthocyanins, which are richly present in C. nervosum var. paniala, can be used as a natural coloring agent (Boo et al., 2012). C. nervosum var. paniala fruit extracts were tested for natural coloring property. The hydrochloric ethanol extract of C. nervosum var. paniala fruit (HEECF) was mixed with a stable base and used as a coloring spray; it was tested on human volunteers. The results showed that HEECF based natural hair coloring was feasible and stable under accelerated test, and it retained up to 5 washes. The results of the study suggest that HEECF could be a promising natural colorant in cosmetic preparations without any adverse effects (Pipattanamomgkol et al., 2018).

\section{Concluding remarks}

Though several studies have reported the bioactive constitution of the different parts of the C. nervosum var. paniala plant, a detailed biochemical report is missing. The functional properties and bioactivity of C. nervosum var. paniala were mainly influenced by the extraction method and concentration techniques. Thus, an optimized extraction method has to be determined to obtain superior quality extracts. Further detailed studies are needed to reveal the mechanisms behind the health benefits of this species. The anthocyanin content of berry fruit, especially cyanidin-3-O-glucoside, improves inflammatory bowel disease by reducing cytokine-induced inflammation in intestinal cells (Serra et al., 2013) in addition to showing anti-allergic activity by suppressing interleukin 4 and 13 in T cells (Pyo et al., 2014). Additionally, it was able to protect human endothelial cells from TNF- $\alpha$, by mediating leukocyte adhesion, accumulation of hydrogen peroxide and other oxidant molecules as well as regulating the activation of NF- $\kappa B$ (Ferrari et al., 2017; Speciale et al., 2010). Thus more research on the functional and biological properties of C. nervosum var. paniala will be useful in developing new therapies. With proper scientific evidence, this berry fruit can be used in the food, pharmaceutical, and cosmetic industries.

\section{Acknowledgements}

MIP wishes to thank the Ratchadaphiseksomphot Endowment Fund for Postdoctoral Fellowship and Chulalongkorn University, Thailand, for the support. BSS and CC gratefully acknowledge the Chiang Mai University-grant (CMU-grant), Chiang Mai University, Thailand for the support.

\section{References}

Andres-Lacueva, C., Shukitt-Hale, B., Galli, R. L., Jauregui, O., Lamuela-Raventos, R. M., \&Joseph, J. A. (2005). Anthocyanins in aged blueberry-fed rats are found centrally and may enhance memory.Nutritional Neuroscience, 8(2), 111-120. http://dx.doi. org/10.1080/10284150500078117. PMid:16053243.

Azuma, I. (1987). Immunostimulants now and tomorrow. Tokyo: Japan Scientific Societies Press.

Belancic, A., Agosin, E., Ibacache, A., Bordeu, E., Baumes, R., Razungles, A., \&Bayonove, C. (1997). Influence of sun exposure on the aromatic composition of chileanmuscat grape cultivars moscatel de alejandria and moscatelrosada.American Journal of Enology and Viticulture, 48, 181-186.

Bishayee, A., Mbimba, T., Thoppil, R. J., Háznagy-Radnai, E., Sipos, P., Darvesh, A. S., Folkesson, H. G., \&Hohmann, J. (2011). Anthocyanin rich black currant (Ribesnigrum L.) extract affords chemoprevention against diethylnitrosamine-induced hepatocellular carcinogenesis in rats. The Journal of Nutritional Biochemistry, 22(11), 1035-1046. http://dx.doi.org/10.1016/j.jnutbio.2010.09.001. PMid:21216582.

Boo, H. O., Hwang, S. J., Bae, C. S., Park, S. H., Heo, B. G., \&Gorinstein, S. (2012). Extraction and characterization of some natural plant pigments.Industrial Crops and Products, 40, 129-135. http://dx.doi. org/10.1016/j.indcrop.2012.02.042.

Butterfield, D. A., Perluigi, M., \&Sultana, R. (2006). Oxidative stress in Alzheimer's disease brain: new insights from redox proteomics. European Journal of Pharmacology, 545(1), 39-50. http://dx.doi. org/10.1016/j.ejphar.2006.06.026. PMid:16860790.

Chaisawadi, S., \&Methawiriyasilp, W. (2008). Clean production of commercial 'Makiang' juice processing for medicinal herbs and health benefits.Acta Horticulturae, (786), 201-208. http://dx.doi. org/10.17660/ActaHortic.2008.786.22.

Chaiyasut, C., Sivamaruthi, B. S., Pengkumsri, N., Sirilun, S., Peerajan, S., Chaiyasut, K., \&Kesika, P. (2016). Anthocyanin profile and its antioxidant activity of widely used fruits, vegetables, and flowers in Thailand.Asian Journal of Pharmaceutical and Clinical Research, 9(6), 218-224. http://dx.doi.org/10.22159/ajpcr.2016.v9i6.14245.

Charoensin, S., Taya, S., Wongpornchai, S., \&Wongpoomchai, R. (2012). Assessment of genotoxicity and antigenotoxicity of an aqueous extract of Cleistocalyx nervosum var. paniala in in vitro and in vivo models.Interdisciplinary Toxicology, 5(4), 201-206. http://dx.doi. org/10.2478/v10102-012-0033-2. PMid:23554564.

Cuypers, A., Plusquin, M., Remans, T., Jozefczak, M., Keunen, E., Gielen, H., Opdenakker, K., Nair, A. R., Munters, E., Artois, T. J., Nawrot, T., Vangronsveld, J., \&Smeets, K. (2010). Cadmium stress: an oxidative challenge.Biometals, 23(5), 927-940. http://dx.doi. org/10.1007/s10534-010-9329-x. PMid:20361350.

Desjardins, J., Tanabe, S., Bergeron, C., Gafner, S., \&Grenier, D. (2012). Anthocyanin-rich black currant extract and cyanidin-3-O-glucoside have cytoprotective and anti-inflammatory properties.Journal of Medicinal Food, 15(12), 1045-1050. http://dx.doi.org/10.1089/ jmf.2011.0316. PMid:22738124.

Ferrari, D., Cimino, F., Fratantonio, D., Molonia, M. S., Bashllari, R., Busà, R., Saija, A., \&Speciale, A. (2017). Cyanidin-3-O-glucoside modulates the in vitro inflammatory crosstalk between intestinal epithelial and endothelial cells.Mediators of Inflammation, 2017, 3454023. http://dx.doi.org/10.1155/2017/3454023. PMid:28373746.

Inboot, W., Taya, S., Chailungka, A., Meepowpan, P., \&Wongpoomchai, R. (2012). Genotoxicity and antigenotoxicity of the methanol extract of Cleistocalyx nervosum var. paniala seed using a Salmonella mutation assay and rat liver micronucleus tests.Molecular \& Cellular Toxicology, 8(1), 19-24. http://dx.doi.org/10.1007/s13273-012-0003-y. 
Lee, Y. M., Yoon, Y., Yoon, H., Park, H. M., Song, S., \&Yeum, K. J. (2017). Dietary anthocyanins against obesity and inflammation.Nutrients, 9(10), 1089. http://dx.doi.org/10.3390/nu9101089. PMid:28974032.

Leelapornpisit, P., Khansuwan, U., Kittipongpattana, N., \&Rojanakul, J. (2004). Chemical properties and antioxidant activities of Makiang seed extract for functional food and cosmetic used. In Proceedings of theResearch and Development of Functional Food Products Symposium II. Chiangmai, Thailand.

Liawruangrath, B., Liawruangrath, S., Thongchai, W., \&Machan, T. (2005). Determination of malic acid and citric acid in ripe berries of Eugenia paniala Roxb. by high performance liquid chromatography. In Proceedings of the $31^{\text {st }}$ Congress on Science and Technology of Thailand at Technopolis. Nakhon Ratchasima, Thailand: Suranaree University of Technology.

Maisuthisakul, P., Suttajit, M., \&Pongsawatmanit, R. (2007). Assessment of phenolic content and free radical scavenging capacity of some Thai indigenous plants.Food Chemistry, 100(4), 1409-1418. http:// dx.doi.org/10.1016/j.foodchem.2005.11.032.

Manosroi, J., Chankhampan, C., Kumguan, K., Manosroi, W., \&Manosroi, A. (2015). In vitro anti-aging activities of extracts from leaves of Ma-Kiang (Cleistocalyx nervosum var. paniala).Pharmaceutical Biology, 53(6), 862-869. http://dx.doi.org/10.3109/13880209.2014. 946058. PMid:25431131.

Nuengchamnong, N., \&Ingkaninan, K. (2009). On-line characterization of phenolic antioxidants in fruit wines from family myrtaceae by liquid chromatography combined with electrospray ionization tandem mass spectrometry and radical scavenging detection. Lebensmittel-Wissenschaft + Technologie, 42(1), 297-302. http:// dx.doi.org/10.1016/j.lwt.2008.04.012.

Patthamakanokporn, O., Puwastien, P., Nitithamyong, A., \&Sirichakwal, P. P. (2008). Changes of antioxidant activity and total phenolic compounds during storage of selected fruits.Journal of Food Composition and Analysis, 21(3), 241-248. http://dx.doi.org/10.1016/j.jfca.2007.10.002.

Pipattanamomgkol, P., Lourith, N., \&Kanlayavattanakul, M. (2018). The natural approach to hair dyeing product with Cleistocalyx nervosum var. paniala.Sustainable Chemistry and Pharmacy, 8, 88-93. http:// dx.doi.org/10.1016/j.scp.2018.04.001.

Poontawee, W., Natakankitkul, S., \&Wongmekiat, O. (2016). Protective effect of Cleistocalyx nervosum var. paniala fruit extract against oxidative renal damage caused by cadmium.Molecules, 21(2), 133. http://dx.doi.org/10.3390/molecules21020133. PMid:26805807.

Praticò, D. (2008). Oxidative stress hypothesis in Alzheimer's disease: a reappraisal.Trends in Pharmacological Sciences, 29(12), 609-615. http://dx.doi.org/10.1016/j.tips.2008.09.001. PMid:18838179.

Pyo, M. Y., Yoon, S. J., Yu, Y., Park, S., \&Jin, M. (2014). Cyanidin-3glucoside suppresses Th2 cytokines and GATA-3 transcription factor in EL-4 T cells.Bioscience, Biotechnology, and Biochemistry, 78(6), 1037-1043. http://dx.doi.org/10.1080/09168451.2014.9121 15. PMid:25036132.

Reynolds, A. G., Wardle, D. A., Hall, J. W., \&Dever, M. (1995). Fruit maturation of four Vitis vinifera cultivars in response to vineyard location and basal leaf removal.American Journal of Enology and Viticulture, 46, 542-558.

Sarkar, A., Ravindrani, G., \&Krishnamurthy, V. (2013). A brief review on the effect of cadmium toxicity: from cellular to organ level. International Journal of Biotechnology and Research, 3, 17-36.

Serra, D., Paixao, J., Nunes, C., Dinis, T. C., \&Almeida, L. M. (2013). Cyanidin-3-glucoside suppresses cytokine-induced inflammatory response in human intestinal cells: comparison with 5-amino salicylic acid.PLoS One, 8(9), e73001. http://dx.doi.org/10.1371/ journal.pone.0073001. PMid:24039842.

Slemmer, J. E., \&Weber, J. T. (2014). Assessing antioxidant capacity in brain tissue: methodologies and limitations in neuroprotective strategies.Antioxidants, 3(4), 636-648. http://dx.doi.org/10.3390/ antiox3040636. PMid:26785231.

Speciale, A., Canali, R., Chirafisi, J., Saija, A., Virgili, F., \&Cimino, F. (2010). Cyanidin-3-O-glucoside protection against TNF- $a$-induced endothelial dysfunction: involvement of nuclear factor- $\mathrm{\kappa B}$ signaling. Journal of Agricultural and Food Chemistry, 58(22), 12048-12054. http://dx.doi.org/10.1021/jf1029515. PMid:20958056.

Sriwanthana, B., Treesangsri, W., Boriboontrakul, B., Niumsakul, S., \&Chavalittumrong, P. (2007). In vitro effects of Thai medicinal plants on human lymphocyte activity.Songklanakarin Journal of Science and Technology, 29(Suppl. 1), 17-28.

Sukprasansap, M., Chanvorachote, P., \&Tencomnao, T. (2017). Cleistocalyx nervosum var. paniala berry fruit protects neurotoxicity against endoplasmic reticulum stress-induced apoptosis.Food and Chemical Toxicology, 103, 279-288. http://dx.doi.org/10.1016/j. fct.2017.03.025. PMid:28315776.

Tantratian, S., Balmuang, N., \&Krusong, W. (2019). Phenolic enrichment of Ma-Kieng seed extract using absorbent and this enriched extract application for safety control of fresh-cut cantaloupe.LebensmittelWissenschaft + Technologie, 106, 105-112. http://dx.doi.org/10.1016/j. lwt.2019.01.049.

Taya, S., Punvittayagul, C., Chewonarin, T., \&Wongpoomchai, R. (2009). Effect of aqueous extract from Cleistocalyx nervosum on oxidative status in rat liver.Thai Journal of Toxicology, 24, 101-105.

Taya, S., Punvittayagul, C., Inboot, W., Fukushima, S., \&Wongpoomchai, R. (2014). Cleistocalyx nervosum extract ameliorates chemical-induced oxidative stress in early stages of rat hepatocarcinogenesis.Asian Pacific Journal of Cancer Prevention, 15(6), 2825-2830. http://dx.doi. org/10.7314/APJCP.2014.15.6.2825. PMid:24761908.

Thongma, S. (2002). Botanical description of Makiang (pp. 66-96). Bangkok: Lampang Agricultural Research and Training Center.

Thuschana, W., Thumvijit, T., Chansakaow, S., Ruamrungsri, S., \&Wongpoomchai, R. (2012). Chemical constituents and antioxidant activities of Cleistocalyx nervosum fruits in in vitro and in vivo models. Thai Journal of Toxicology, 27, 194-208.

Valko, M., Jomova, K., Rhodes, C. J., Kuča, K., \&Musílek, K. (2016). Redox- and non-redox-metal-induced formation of free radicals and their role in human disease.Archives of Toxicology, 90(1), 1-37. http://dx.doi.org/10.1007/s00204-015-1579-5. PMid:26343967. 